\title{
Epidemiology of Haemophilus influenzae type b invasive disease in Wales
}

\author{
A I Howard, K T Dunkin, J M Musser, S R Palmer
}

Abstract

Objective-To investigate the epidemiology of invasive disease due to Haemophilus influenzae type $b$, the clones responsible, and the antibiotic resistance of the isolates.

Design-Prospective population based analysis of clinical and epidemiological data collected for Gwynedd during 1980-90 and in the whole of Wales during 1988-90.

Setting - 19 hospitals in Wales; all medical microbiology laboratories in Wales participated.

Patients -82 patients with confirmed invasive infections caused by $H$ influenzae type $b$ in Gwynedd during 1980-90 and 207 in Wales during 1988-90.

Main outcome measures-Clinical and epidemiological measures; analysis of the clonal types of the isolates based on the electrophoretic mobilities of 17 metabolic enzymes; and antibiotic resistance.

Results-The annual incidence of $H$ influenzae type b infections in Gwynedd was 3.2 cases/100 000 and in Wales was 2.5 cases $/ 100000$. Most cases occurred in children aged under 5 years, the highest annual incidence being in those aged under 1 $(84.6 / 100000$ and $56.9 / 100000$ in Wales). The cumulative risk of acquiring $H$ influenzae type b disease by the fifth birthday was one in 456 in Gwynedd and one in $\mathbf{5 7 8}$ in Wales. Fifteen per cent of cases in Gwynedd and 7\% of those in Wales occurred in adults. Predominant clinical conditions were meningitis in children and pneumonia in adults. In Gwynedd 2/70 (3\%) children and 5/12 (42\%) adults died. Long term neurological sequelae occurred in $8 \%(4 / 48)$ of children who survived haemophilus meningitis. Children presenting with infection were usually the youngest members of their family. No secondary household cases were identified. 100 of $128(78 \%)$ strains were of a single clone, electrophoretic type $12 \cdot 5$, and $4 / 207(1.9 \%)$ isolates from Wales were resistant to both ampicillin and chloramphenicol.

Conclusions-The annual rate of infection in children aged under 5 in four Welsh counties was $12-44 \%$ higher than that previously published for the United Kingdom. The study emphasises the potential value of a vaccine effective in early infancy and provides baseline data to assess its efficacy after its introduction. Alternatives to ampicillin and chloramphenicol should be used as first line, empirical treatment for severe infections that might be caused by $H$ influenzae type $b$ in Wales.

\section{Introduction}

Haemophilus influenzae type $\mathrm{b}$ is responsible for various invasive infections including meningitis, epiglottitis, pneumonia, and septic arthritis which predominantly occur in children under 5 years of age. In recent years vaccines have been developed by covalent coupling of the type b capsule (polyribosyl ribitol phosphate) or oligosaccharides derived from it to carrier proteins. ' 2 These invoke an immune response in young infants and provide significant protection against Haemophilus influenzae type $\mathrm{b}$ disease. ${ }^{3}$ To assess the potential value of these vaccines for a given population it is important to have a comprehensive understanding of the epidemiology of infections due to this organism so that the groups at greatest risk can be identified, the cost-benefit of vaccine introduction can be estimated, and a baseline for the incidence of infections can be established to provide a measure of the efficacy of any vaccination programme. An analysis of the strains responsible for disease is also needed to determine whether their clonal type changes with time. In the United Kingdom published information relating to these subjects is limited. We present results generated from two prospective, population based studies conducted in Wales. They were begun in Gwynedd, a rural county in North Wales, in 1980 and in the whole of Wales in 1988. Analysis of the clonal types of Haemophilus influenzae type b isolates was undertaken by examining the electrophoretic mobilities of 17 metabolic enzymes. ${ }^{45}$

\section{Methods}

Invasive diseases due to Haemophilus influenzae type b were defined as systemic infections in which the organism was recovered from cultures of normally sterile tissues or body fluids or in which $H$ influenzae type b antigen was detected in specimens in which haemophilus-like Gram negative bacilli were seen but not cultured. Cases of pneumonia were accepted as being caused by $H$ influenzae only if they were associated with positive blood cultures.

In Gwynedd a prospective study has been in progress since 1980. Diagnosis, any predisposing factor, date of presentation, age, place of residence, sibling status, and outcome are recorded. Outcome is based on routine paediatric follow up and assessment by senior medical officers dealing with child development. A similar study in Wales as a whole began in January 1988, under the auspices of the Welsh Standing Specialist Advisory Group in Microbiology involving all the clinical microbiology laboratories in Wales. The information collected in the study of the whole of Wales has been restricted to a patient's age, principal diagnosis, underlying diseases, and town or village of residence. This is recorded on a notification form forwarded to the laboratory in Bangor, together with a subculture of the organism responsible. The coordinating laboratory confirms the identity of the organisms and their antibiotic susceptibilities. Cases arising in Gwynedd in 1988-90 were included in both data sets.

Organisms were accepted as being $H$ influenzae if they were Gram negative, nutritionally dependent on $\mathrm{X}$ and $\mathrm{V}$ factors, incapable of producing porphyrins from $\delta$-aminolaevulinic acid, non-haemolytic on horse blood agar, and non-carbon dioxide requiring. Colonies were examined for iridescence on Filde's agar and serotyped with agglutinating serum obtained from the Public Health Laboratory Service. Clonal analysis based on the electrophoretic mobilities of 17 metabolic enzymes was undertaken on strains isolated from Wales in 1988-9 in the laboratory of JMM by methods previously described. ${ }^{45}$ The methods used for 
determining antibiotic susceptibilities and the criteria accepted for resistance were those outlined by Howard and Williams. ${ }^{6}$

The incidences of infection for Gwynedd during 1980-90 were calculated with 1985 population estimates, and for Wales during 1988-90 with 1988 estimates. ${ }^{78}$ Data from Powys were excluded from these analyses as this district has no general hospital and patients are commonly admitted to English hospitals not included in the study.

\section{Results}

Eighty two cases of invasive disease due to $H$ influenzae type b occurred in Gwynedd between 1980 and 1990 , and 207 occurred in Wales between 1988 and 1990.

Clinical presentation-Meningitis was the most common illness (table I), comprising $62 \%$ of infections in Gwynedd and $58 \%$ in Wales. The median age of presentation for children aged under 5 years with meningitis was 14 months in Gwynedd (range 2-54 months) and in Wales (1-54 months). Epiglottitis

TABLE I-Invasive disease due to Haemophilus influenzae type $b$. Figures are numbers (percentages)

\begin{tabular}{lcc}
\hline Principal diagnosis & Gwynedd 1980-90 & Wales 1988-90 \\
\hline Meningitis & $51(62)$ & $120(58)$ \\
Epiglottitis & $8(10)$ & $32(16)$ \\
Pneumonia & $7(9)$ & $16(8)$ \\
Bone and joint infection & $11(13)$ & $10(5)$ \\
Bacteraemia* & $1(1)$ & $15(7)$ \\
Cellulitis & $1(1)$ & $11(5)$ \\
Other & $3(4)$ & $3(1)$ \\
\hline Total & 82 & 207 \\
\hline
\end{tabular}

^No obvious focus of infection.
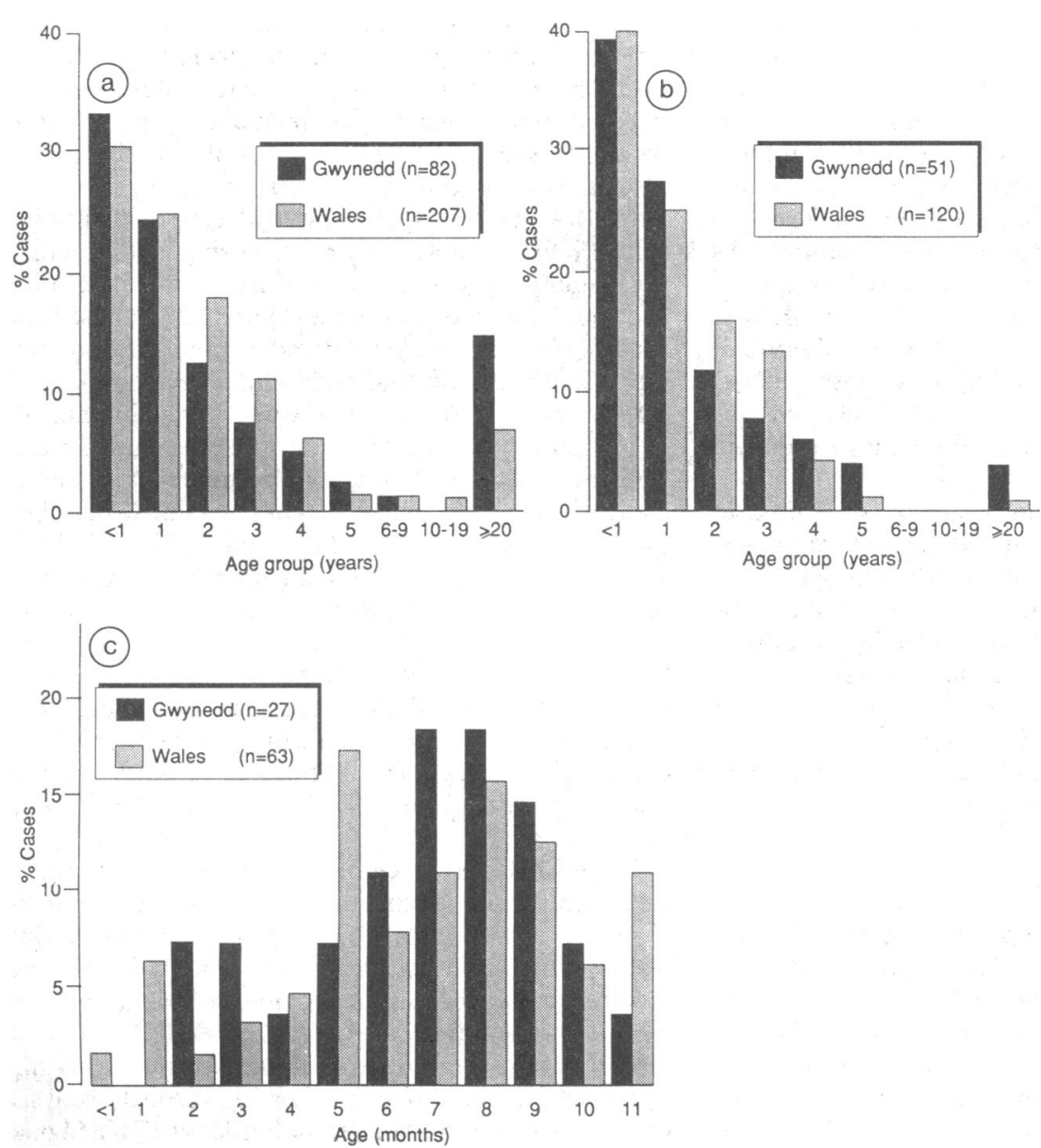

Distribution of invasive disease due to $H$ influenzae type b according to age, Gwynedd, 1980-90, and Wales, 1988-90. (a) All cases; (b) meningitis; and (c) all cases in children aged below 1 year. Values are numbers of cases as a percentage of total number tended to occur in older children (median age 27 (range 5-38) months in Gwynedd, 29 (1-54) months in Wales). In contrast with childhood infections, pneumonia was the commonest condition in adults, representing 5/12 $(42 \%)$ cases in Gwynedd and $7 / 15(47 \%)$ in Wales. Proportionately more bone and joint infections (septic arthritis $17 / 20$ cases) were seen in Gwynedd than in Wales $\left(\chi^{2}=5 \cdot 2, p=0 \cdot 02\right)$.

Outcome-Data were available only for Gwynedd, where $7 / 82(9 \%)$ patients died. This included $5 / 12$ $(42 \%)$ adults and $2 / 70(3 \%)$ children. One of $49(2 \%)$ children with meningitis died. Four of the survivors exhibited long term complications: three had developmental delay, with varying degrees of communication and behavioural problems. Audiometric testing was performed on $34 / 48$ children who had had meningitis. One of those with developmental delay had a mild, unilateral sensorineural hearing loss. Another had a mild, bilateral, sensorineural deficit. Four had persistent deafness associated with otitis media with effusion. All of these children were subsequently shown to have normal audiograms after treatment.

Predisposing factors-Predisposing factors for $H$ influenzae infection were identified in $3 / 70(4 \%)$ children living in Gwynedd and 2/192 (1\%) in Wales and comprised fractured skull (one child), severe developmental abnormalities (one), splenectomy (one), and presence of a ventriculoperitoneal shunt (two). Underlying diseases were more common in adults, being reported in 5/12 (42\%) patients in Gwynedd and $2 / 15(13 \%)$ in Wales. They comprised fractured skull, myocardial infarction, severe osteoarthritis, Down's syndrome, chronic lymphatic leukaemia, lymphoma, and diabetes.

Sex-There was a small predominance of males among the children with $H$ influenzae disease, the male to female ratio being $1 \cdot 2: 1$ for Gwynedd and $1 \cdot 1: 1$ for Wales; the differences in the sex ratios were not significant.

Family structure - There was one sibling or more in households of $47 / 57$ (82\%) children under 15 years of age with infection living in Gwynedd for whom family information was available. The subject presenting with infection was the youngest in $41 / 47(87 \%)$ cases. Among the 57 cases there were four sibling contacts aged $<1$ year, 12 aged $<2$ years, 17 aged $<3,27$ aged $<4$, and 31 aged $<5$. No secondary household cases were identified.

Incidence of infection-Table II and the figure show the incidence of $H$ influenzae type $\mathrm{b}$ infections in different age groups. Most patients were under 5 years of age, and the highest incidence was in children aged under 1 . Most infections in infants occurred between 5 and 9 months of age (19/27, 70\% in Gwynedd and $41 / 63,65 \%$ in Wales). Overall, $6 \%$ (5/82) of infections in Gwynedd and 5\% (11/207) of those in Wales were seen in patients aged under 5 months. The annual incidence of invasive $H$ influenzae type b disease in children aged less than 5 years was $43 \cdot 8 / 100000$ based on figures for Gwynedd (1980-90) and 34.6/100 000 for Wales (1988-90). The annual incidence of meningitis for this age group was 30.7/100000 in Gwynedd and $22 \cdot 0 / 100000$ in Wales. Fifteen per cent of cases in Gwynedd and $7 \%$ of those in Wales occurred in adults, and some increased susceptibility to disease was observed in subjects aged 75 and over (table II).

County of residence-Table III shows the incidence of $H$ influenzae type $\mathrm{b}$ infections in children less than 5 years old for seven Welsh counties in 1988-90. Only in Dyfed was the incidence of invasive disease significantly different from the average incidence of Wales.

Annual variation - Table IV shows the annual occurrence of $H$ influenzae type $\mathrm{b}$ infections in Gwynedd with those caused by Neisseria meningitidis for comparison. In Wales 54, 89, and 64 cases of $H$ influenzae 
TABLE II-Annual incidence of invasive infections due to $H$ influenzae type $b$ in Wales per 100000 population by age (number of cases)

\begin{tabular}{|c|c|c|c|c|c|c|}
\hline \multirow[b]{2}{*}{ Age (years) } & \multicolumn{3}{|c|}{ Gwynedd, 1980-90 } & \multicolumn{3}{|c|}{ Wales, 1988-90 } \\
\hline & Total & Meningitis & Other & Total & Meningitis & Other \\
\hline$<1$ & $84 \cdot 6(27)$ & $62 \cdot 7(20)$ & $21 \cdot 9(7)$ & $56 \cdot 9(63)$ & $43 \cdot 4(48)$ & $13 \cdot 5(15)$ \\
\hline $1-4$ & $33 \cdot 1(40)$ & $22 \cdot 3(27)$ & $10 \cdot 8(13)$ & $28 \cdot 8(123)$ & $16 \cdot 4(70)$ & $12 \cdot 4(53)$ \\
\hline $5-15$ & $0.8(3)$ & $0.5(2)$ & $0 \cdot 3(1)$ & $0.5(6)$ & $0 \cdot 1(1)$ & $0.4(5)$ \\
\hline $16-64$ & $0.4(6)$ & $0 \cdot 1(1)$ & $0 \cdot 3(5)$ & $0 \cdot 1(7)$ & & $0 \cdot 1(7)$ \\
\hline $65-74$ & $0 \cdot 8(2)$ & & $0 \cdot 8(2)$ & $0 \cdot 4(3)$ & & $0.4(3)$ \\
\hline$\geqslant 75$ & $1.9(4)$ & $0 \cdot 5(1)$ & $1 \cdot 4(3)$ & $0.9(5)$ & $0 \cdot 2(1)$ & $0 \cdot 7(4)$ \\
\hline Total & $3 \cdot 2(82)$ & $2 \cdot 0(51)$ & $1 \cdot 2(31)$ & $2 \cdot 5(207)$ & $1 \cdot 5(120)$ & $1.0(87)$ \\
\hline
\end{tabular}

TABLE III - Invasive infections due to $H$ influenzae type $b$ in children aged under 5 years and incidence, 1988-90, according to county of residence

\begin{tabular}{lcc}
\hline County & Total & $\begin{array}{c}\text { Cases/100 000/year } \\
(95 \% \text { confidence interval })\end{array}$ \\
\hline Gwynedd $(14200)$ & 21 & $49 \cdot 3(28 \cdot 2$ to $70 \cdot 4)$ \\
Clwyd $(25700)$ & 36 & $46 \cdot 7(31 \cdot 5$ to $61 \cdot 9)$ \\
Dyfed $(21300)$ & 10 & $15 \cdot 6(6 \cdot 0$ to $25 \cdot 3)$ \\
West Glamorgan $(23100)$ & 24 & $34 \cdot 6(20 \cdot 8$ to $48 \cdot 5)$ \\
Mid Glamorgan $(36900)$ & 25 & $22 \cdot 6(13 \cdot 7$ to $31 \cdot 4)$ \\
South Glamorgan $(28300)$ & 36 & $42 \cdot 4(28 \cdot 6$ to $56 \cdot 2)$ \\
Gwent $(29700)$ & 34 & $38 \cdot 2(25 \cdot 3$ to $51 \cdot 0)$ \\
\hline Total $(179200)$ & 186 & $34 \cdot 6(29 \cdot 6$ to $39 \cdot 6)$ \\
\hline
\end{tabular}

^Number of children aged less than 5 years. ${ }^{*}$

TABLE IV - Invasive meningococcal and Haemophilus influenzae type b disease, Gwynedd 1980-90

Year

$\begin{array}{llllllllllll}\text { Total } & 1980 & 1981 & 1982 & 1983 & 1984 & 1985 & 1986 & 1987 & 1988 & 1989 & 1990\end{array}$

\begin{tabular}{|c|c|c|c|c|c|c|c|c|c|c|c|c|}
\hline $\begin{array}{l}\text { Disease due to: } \\
\text { D pringitidis }\end{array}$ & & & 1 & 0 & 1 & 0 & 4 & & & & 9 & \\
\hline $\begin{array}{l}N \text { meningitidis } \\
H \text { influenzae type } \mathrm{b}\end{array}$ & $\begin{array}{l}50 \\
82\end{array}$ & $\begin{array}{l}3 \\
6\end{array}$ & $\begin{array}{l}1 \\
4\end{array}$ & 7 & $\begin{array}{l}1 \\
8\end{array}$ & 7 & $\begin{array}{l}4 \\
6\end{array}$ & 11 & $\begin{array}{r}11 \\
5\end{array}$ & 7 & 10 & 11 \\
\hline
\end{tabular}

TABLE V-Clones of $H$ influenzae type $b$ isolated from patients with invasive disease, Wales 1988-9

No associated with:

Electrophoretic type Total Meningitis Epiglottitis Bacteraemia Pneumonia Cellulitis Arthritis Other

\begin{tabular}{|c|c|c|c|c|c|c|c|c|}
\hline 1.9 & 3 & 2 & & 1 & & & & \\
\hline $12 \cdot 0$ & 1 & 1 & & & & & & \\
\hline $12 \cdot 5$ & 100 & 53 & 16 & 8 & 10 & 7 & 4 & 2 \\
\hline $12 \cdot 6$ & 1 & 1 & & & & & & \\
\hline $12 \cdot 7$ & 7 & 4 & & & 2 & 1 & & \\
\hline $12 \cdot 8$ & 7 & 5 & & 2 & & & & \\
\hline 12.9 & 1 & 1 & & & & & & \\
\hline 21.9 & 1 & & 1 & & & & & \\
\hline $25 \cdot 6$ & 2 & 2 & & & & & & \\
\hline Others & 5 & 3 & & 1 & & & 1 & \\
\hline Total & 128 & 72 & 17 & 12 & 12 & 8 & 5 & 2 \\
\hline
\end{tabular}

type b infection were recorded in 1988, 1989, and 1990 respectively.

Season-Infections arose more commonly in the winter months. Between October and March $61 \%$ were recorded in Gwynedd and $66 \%$ in Wales.

$H$ influenzae type $b$ clones-Table $\mathrm{V}$ shows the multilocus enzyme genotypes (electrophoretic types (ET)s) of 128 strains of $H$ influenzae type b isolated from patients in Wales in 1988-9. There was a high degree of homogeneity: 100 isolates were electrophoretic type 12.5 and 117 were assigned to electrophoretic types of the type 12 clone family. A lower percentage of meningitis cases were caused by strains of type $12.5(74 \%)$ than the percentage of other conditions $(84 \%)$, but this difference was not significant.

Antibiotic resistance-Ampicillin resistance was identified in $15.9 \%$ of $H$ influenzae type b isolates from Gwynedd and $12 \cdot 6 \%$ of isolates from Wales. All resistant strains produced $\beta$ lactamase. The clones of the $22 \beta$ lactamase producing strains isolated in Wales in 1988-9 comprised electrophoretic types 12.5 (17 strains); $12 \cdot 7$ (two); and $12 \cdot 8,12 \cdot 9$, and undesignated (one each). Four (1.9\%) epidemiologically distinct strains isolated from patients in Wales (three from cases of meningitis) in $1988-90$ were resistant to chloramphenicol and inactivated the drug in vitro; they were also resistant to ampicillin.

\section{Discussion}

The participation of all medical microbiology laboratories in Wales ensured that all confirmed cases of systemic infection caused by $H$ influenzae type b treated in hospitals in the country were recorded. The figures quoted for the incidence of disease in the population, however, should be considered only as minimum estimates. Any residents in Wales who might have been admitted to hospitals outside Wales were not included. Nor were any allowances made for cases that might have occurred without the opportunity for definitive bacteriological diagnosis. Despite these limitations the annual incidence of $H$ influenzae type b invasive disease derived for children less than 5 years old was higher than has been previously recorded in the United Kingdom. ${ }^{9.11}$ The incidence was $12-44 \%$ greater in four counties than the maximum previous estimate (33/100000), ${ }^{9}$ and cases have been arising consistently at rates roughly equivalent to the upper level for at least 11 years in one county (Gwynedd). The cumulative risk for children acquiring $H$ influenzae type $b$ disease by their fifth birthday was one in 456 in Gwynedd and one in 578 for Wales as a whole, values comparable with those recorded in several American states $^{12}$ and in Finland before introduction of large scale immunisation. ${ }^{13}$ In Gwynedd there was no clearcut trend in the annual variation in the number of cases, in contrast with meningococcal infections, whose incidence increased appreciably in the second half of the decade. Despite this increase, which occurred at a time when laboratory reports of $N$ meningitidis infections were higher in England and Wales than had been recorded since 1974 (PHLS Communicable Diseases Surveillance Centre, unpublished information), 64\% more $H$ influenzae type b infections than $N$ meningitidis infections were seen during the 11 year study period.

The mortality of $2 \%$ among children with meningitis in Gwynedd was similar to other recorded rates of $2 \%$ $8 \%$. $^{9-12} 14$ Four of the survivors had long term neurological sequelae. This complication rate may underestimate the true impact of haemophilus meningitis as audiometric assessments were incomplete, and well controlled, long term, follow up data to assess less obvious complications such as mild learning difficulties, diminished intellectual attainment, perceptual and attentional deficits, and minor behavioural problems were not available. Where such information has been obtained long term sequelae have been shown to be present in as many as a third to a half of children surviving haemophilus meningitis, ${ }^{15} 16$ although other studies have shown a more favourable outcome..$^{1 / 14}$

The pattern of $H$ influenzae type $\mathrm{b}$ infections in children suggests that to achieve maximum benefit any $H$ influenzae type b vaccine should be effective in early infancy. Current evidence suggests that new conjugate vaccines are immunogenic and produce a response that can be boosted in children as young as 2 months of age. ${ }^{20}$ As most cases in infants occur after 4 months of age administration of the vaccine with the diphtheria/ tetanus/pertussis vaccine (at 2, 3, and 4 months of age in the United Kingdom) could prevent most cases of $H$ influenzae type $b$ disease that might otherwise arise.

There has been no previous population based estimate of the incidence of invasive infections due to $H$ influenzae type $\mathrm{b}$ in adults in the United Kingdom, and few data are available from other parts of the 
world. Results for Sweden 21 and Finland 22 resemble those for Wales and also highlight the predominance of pulmonary infections and the higher mortality and more common association with underlying disease than is seen in children. The Finnish study noted that subtypes uncommonly associated with infections in children were more common in adults. ${ }^{22}$ This was not seen in Wales, where $90 \%$ of adult isolates were electrophoretic type 12.5 and $10 \%$ electrophoretic type $12 \cdot 7$. There is some evidence to suggest that the large scale introduction of $H$ influenzae type b vaccine in children might lead to a fall in the carriage rates of the organism in the population..$^{23}$ If this occurred it could provide secondary protection for susceptible subjects by reducing their potential contact with the organism. This could result in a decline in the incidence of $H$ influenzae type $\mathrm{b}$ disease in unvaccinated adults reported here.

Strategies for preventing $H$ influenzae type b disease have also focused on the occurrence of secondary disease in close contacts of a case and the need for antibiotic prophylaxis. The highest risk is seen in household contacts and persists for at least 30 days after presentation of the index case. ${ }^{2+}$ Attack rates vary with the age of such contacts and has been put at $6.0 \%$ for children aged under 1 year, $1.5 \%$ for those aged $1-3$, $0 \cdot 1 \%$ for those aged $4-5$, and $0 \%$ for those aged 6 and over. ${ }^{24}$ This has led the American Academy of Pediatrics to recommend that when there is a household contact aged under 4 years the whole family should receive rifampicin prophylaxis. ${ }^{25}$ Similar recommendations have been made recently in the United Kingdom by the Public Health Laboratory Service for contacts less than 3 years old. ${ }^{26}$ We recorded no instances of household transmission. It is not known whether antibiotic prophylaxis might have contributed to this; a review of the family structure of the cases occurring in patients in Gwynedd, however, suggests that the likelihood of secondary household transmission is low. As might be expected from the predominance of infections in early infancy, the person presenting with $H$ influenzae type b disease was usually the youngest member of the family unit and thus the one who would otherwise be most at risk. In only four of the 57 cases for which detailed information was available was there a sibling contact aged under 1 year, and, in total, there were only 27 family contacts aged under 4 years. Given the numbers and age profile of contacts and the attack rates quoted above, only one case of household transmission would have been expected for every 127 children presenting with invasive disease, even if antibiotic prophylaxis had not been given.

Analysis of the electrophoretic mobilities of chromosomally encoded metabolic enzymes has identified 182 distinctive clones of $H$ influenzae type b. Determination of the genotypes of $1975 \mathrm{H}$ influenzae type b strains from 30 countries disclosed that $81 \%$ of isolates could be assigned to one of nine clones. ${ }^{5}$ Three of these, electrophoretic types $1.9,12 \cdot 5$, and 12.8 have a wide distribution but their relative frequency shows appreciable geographic variation. The isolates causing $H$ influenzae type b disease in Wales are predominantly a single clone (12.5), which is also the most common clone causing invasive episodes in virtually all European countries (J Musser, unpublished data). ${ }^{5}$ Only $11 / 128$ $(8.6 \%)$ of strains were not included in the electrophoretic type 12 clone family. Of these, two were type $25 \cdot 6$, a clone rarely encountered in Europe but common in certain parts of the Far East. ${ }^{5}$ There is some evidence to suggest that certain clones have a lower potential for invasiveness than others ${ }^{27}$ and that the predominant subtypes circulating in a population can change with time..$^{28}$ Further studies are required to assess the significance of these findings for $H$ influenzae type $\mathrm{b}$ disease in the United Kingdom. The impact of
$H$ influenzae type b vaccine on clone distribution will be of particular interest.

Significant antibiotic resistance in $H$ influenzae type b was observed when $\beta$ lactamase producing, ampicillin resistant strains were encountered in the early 1970s..$^{.9}$ Subsequently, the prevalence of ampicillin resistance has increased and shows appreciable geographic variation. ${ }^{31}$ The finding that $1.9 \%$ of strains isolated from patients in Wales in 1988-90 $(2.5 \%$ from those with meningitis) were resistant to both ampicillin and chloramphenicol indicates that alternative agents, such as cefotaxime, ${ }^{32}$ should now be used as first line, empirical treatment for serious infections such as childhood meningitis that might be caused hv $H$ influenzae type b.

Laboratories participating in the study were those at Nevill Hall Hospital, Abergavenny; Bronglais Hospital, Aberystwyth; Gwynedd Hospital, Bangor; Princess of Wales Hospital, Bridgend; Caerphilly Miners' District Hospital, Caerphilly; Llandough Hospital, Cardiff; Public Health Laboratory, Cardiff; Royal Infirmary, Cardiff; University Hospital of Wales, Cardiff; West Wales General Hospital, Carmarthen; Withybush General Hospital, Haverfordwest; Llanelli General Hospital; Prince Charles Hospital, Merthyr Tydfil; Neath General Hospital; Royal Gwent Hospital, Newport; East Glamorgan General Hospital, Pontypridd; Morriston Hospital, Swansea; Public Health Laboratory, Swansea; Singleton Hospital, Swansea; Glan Clwyd Hospital, Rhyl; Maelor General Hospital, Wrexham. We thank all the the many microbiology staff, whose diligence has made this study possible, clinicians in Wales who allowed access to patient data, and, in particular, Drs R H Davies and V L. Woolley at Gwynedd Hospital, Bangor. We also thank Miss B Ellis for typing the manuscript, and $\mathrm{Mr} \mathrm{H} \mathrm{M}$ Williams for excellent technical help. The research was supported by NIH grant Al 24332 to R K Selander and by Lilly Industries.

1 Granoff DM, Munson RS. Prospects for prevention of Haemophilus influenzac pe b disease by immunisation. I Infect Dis 1986;153:418-61.

2 Weinberg GA, Granoff DM. Polysaccharide-protein conjugate vaccines for the prevention of Haemophilus influenzac type b disease. I Pediatr 1988;113: 621-31

3 Makela PH, Eskola J, Peltola H, Takala AK, Kayhty H. Clinical experience with Haemophilus influenzae type $\mathrm{h}$ conjugate vaccines. Pediatrics 1990;85: $651-3$

4 Musser JM, Granoff DM, Pattison PE, Sclander RK. A population genetic framework for the study of invasive diseases caused by serotype $\mathrm{b}$ strains of Haemophilus influenzae. Proc Natl Acad Sci USA 1985;82:5078-82.

5 Musser JM, Kroll JS, Granoff DM, et al. Global genetic structure and molecular epidemiology of encapsulated Haemophilus influenzae. Rez Infect Dis 1990;12:75-111.

6 Howard AJ, Williams HM. The prevalence of antibiotic resistance in Haemophilus influenzae in Wales. 7 Antimicrob Chemother 1988;21:251-60. Government Statistical Service. Digest of Welsh statistics. No 32. Cardiff: Welsh Office, 1985 .

8 Government Statistical Service. Digest of W'elsh statistics. No 35. Cardiff: Welsh Office, 1989.

9 Tudor Williams G, Frankland J, Isaacs D, et al. Haemophilus influenzac type b disease in the Oxford region. Arch Dis Child 1989;64:517-9.

10 Goldacre MJ. Acute bacterial meningitis in childhood. Incidence and mortality in a defined population. Lancet 1976; i:28-31.

11 Dyas A, George RH. Ten years' experience of Haemophilus influenzae infection at Birmingham Children's Hospital. I Infect 1986;13:179-85.

12 Broome CV. Epidemiology of Haemophilus influenzae type $b$ infections in the United States. Pediatr Infect Dis. 7 1987;6:779-82.

13 Takala AK, Eskola J, Peltola H, Makela PH. Epidemiology of invasive Haemophilus influenzae type $b$ disease among children in Finland before vaccination with Haemophilus influenzae type b conjugate vaccine. Pediatr Infect Dis f 1989;8:297-302.

14 Davey PG, Cruikshank JK, McManus IC, et al. Bacterial meningitis - ten years experience. $\mathcal{F} \mathrm{Hvg}(\mathrm{Camb})$ 1982;88:383-401.

15 Sproles FT, Azerrad J, Williamson C, et al. Meningtis due to Haemophilus influenzae. Long term sequelac. I Pediatr 1969;75:782-9.

16 Sell SHW, Merrill RE, Doyne RO, et al. Long-term sequelae of Haemophilus influenzae meningitis. Pediatrics 1972;49:206-11.

17 Feigin RD, Stechenber BW, Chang MJ, et al. Prospective evaluation of treatment of Haemophilus influenzae meningitis. $\mathcal{F}$ Pediatr 1976;88:542-8.

8 Tejani A, Dobias B, Sambursky J. Long term prognosis after $\mathrm{H}$ influenzae meningiris: procine 9 Taylor HG, Mills EL, Ciampi A, et al. The sequelae of Haemophilus influenzae meningitis in school-age children. $N$ Engl f Med 1990;323:1657. 63.

20 Camphell H, Byass P, Ahonkai VI, Vella PP, Greenwood BM. Serologic Campbell H, Byass P, Ahonkal VI, Vella PP, Greenwood BM. Serologic responses to an Haemophilus influenzae type b polysaccharide-Neisseria meningitidis outer membrane protein coniur

21 Trollfors B, Claesson B, Lagergard T, Sandberg T. Incidence, predisposing Trollfors B, Claesson B, Lagergard T, Sandberg T. Incidence, predisposing
factors and manifestations of invasive Haemophilus influenzae infections in factors and manifestations of invasive $\mathrm{H}$

22 Takala AK, Eskola J, van Alphen L. Spectrum of invasive Haemophilus influenzae type b disease in adults. Arch Intern Med 1990;150:2573-6. 
23 Takala AK, Eskola J, Nissinen A, Leinonen M, Pekkanen E, Makela PH. Effect of vaccination with Haemophilus influenzae type b (Hib) conjuga vaccine on the oropharyngeal carriage of Hib. In: Programs and abstracts of the 30 th interscience conference on antimicrobial agents and chemotherapy. Atlanta, Georgia: American Society for Microbiology, 1990: 187. (Abstrac 605.

24 Ward JI, Fraser DW, Baraff LJ, Plikaytis BD. Haemophilus influenzae meningitis. A national study of secondary spread in household contacts. N Engl f Med 1979:301:122-6.

25 American Academy of Pediatrics Committee on Infectious Diseases. Revision of recommendations for use of rifampicin prophylaxis of contacts of patients with Haemophilus influenzae infection. Pediatrics 1984;74:301-2.

26 Cartwright KAV, Begg NT, Hull D. Chemoprophylaxis for secondary Haemophilus influenzac tvpe b disease. Communicable Disease Report 1991:1:R2-6

27 Hampton CM. Barenkamp SJ, Granoff DM. Comparison of outer membrane protein subtypes of Hacmophilus influenzae type $b$ isolates from healthy children in the general population and from diseased patients. $f$ Clin
Microbiol 1983:18.596-600.

28 Barenkamp SJ, Granoff DM, Pittman M. Outer membrane protein subtypes and biotypes of Haemophilus influenzae type b: relation between strains isolated in 1934-1954 and 1977-1980. F Infect Dis 1983;148:1127.

29 Gunn BA, Woodall JB, Jones JF, Thornsberry C. Ampicillin-resistant Haemophilus influenzae. Lancet 1974; ;i: 845 .

30 Thomas WJ, McReynolds JW, Mock CR, Bailey DW. Ampicillin-resistant Haemophilus influenzae meningitis. Lancet 1974;i:313.

31 Machka K, Braveny I, Dabernat $\mathrm{H}$, et al. Distribution and resistance patterns of Haemophilus influenzae. A European cooperative study. Eur $\mathrm{f}$ Clin Microbiol Infect Dis 1988;7:14-24.

32 Del Rio MA, Chrane D, Shelton S, McCracken GH, Nelson JD. Ceftriaxone versus ampicillin and chloramphenicol for treatment of bacterial meningitis in children. Lancet 1983;i:1241-4.

(Accepted 24 June 1991)

\section{Deaths from $R h$ haemolytic disease in England and Wales in 1988 and 1989}

\section{Ruth M Hussey, Cyril A Clarke}

\section{University of Liverpool, PO Box 147, Liverpool L69 3BX}

Ruth M Hussey, MFCM, senior lecturer, department of public health

Sir Cyril A Clarke, FRS, honorary Nuffield senior research fellow, department of genetics and microbiology

Correspondence to: $\mathrm{Dr}$ Hussey.

BMf 1991;303:445-6

Since 1977 deaths registered as due to haemolytic disease of the newborn in England and Wales have been analysed in an attempt to identify the circumstances in which the mother became isoimmunised and the effectiveness of anti-D prophylaxis. Information for the years 1977 to 1987 was published by Clarke and Mollison from the research unit of the Royal College of Physicians.' When the unit was reorganised in 1988 the work was transferred to the department of public health, University of Liverpool. We present the results for 1988 and 1989 together with data from earlier years.

\section{Methods and results}

Copies of all the certificates for stillbirths - that is, deaths after the 28th week of pregnancy - and neonatal deaths in England and Wales were sent to us by the Office of Population Censuses and Surveys. The case notes were then provided by the consultant obstetricians.and, when necessary, further information given by general practitioners and regional blood transfusion centres. Details of the inquiry and the categorisation of cases have been reported.

The table shows that the rate of deaths due to haemolytic disease of the newborn has been declining steadily since the research started in 1977 but that in 1988 and 1989 the decline was more dramatic. Thus

Classification of deaths registered by Office of Population Censuses and Surveys as due to haemolytic disease of fetus or newborn, 1977-89

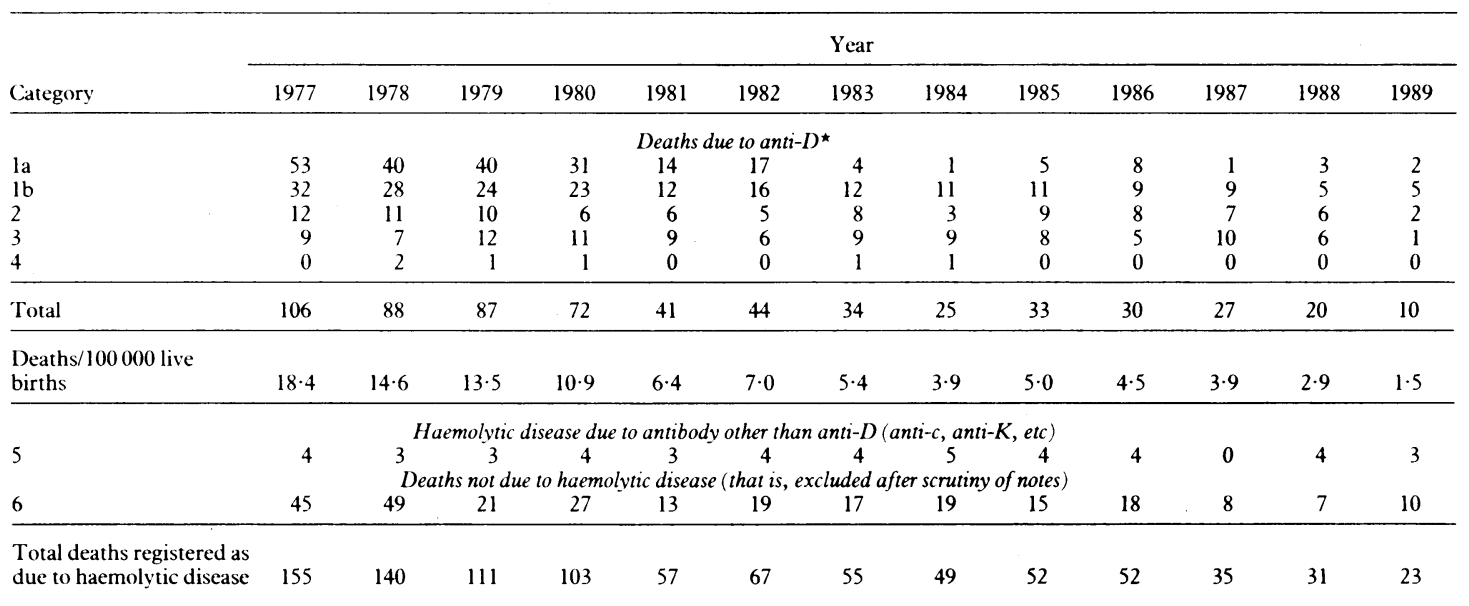

*Category 1: mother believed to have been immunised by pregnancy after which she was not given injection of anti-Rh immunoglobulin (category la, immunising pregnancy occurred before 1970 (when anti-R immunoglobulin not widely available); category $\mathrm{lb}$, immunising pregnancy occurred from 1970 onwards); category 2 : immunised during first pregnancy (anti-D detected during or within seven days after first pregnancy); category 3: immunised despite having been given anti-Rh immunoglobulin after one or more previous pregnancies (failure of prophylaxis); category 4 : immunised against $\mathrm{D}$ by blood transfusion.

\section{Comment}

The low figures for deaths due to haemolytic disease of the newborn during 1988 and 1989 may have been due to chance. A more obvious explanation is improvement in obstetric care leading to fewer deaths, but against this there had been little change in the number of deaths due to antibodies other than $\mathrm{D}$ (for example, $\bar{c}, \mathrm{E}$ or $\mathrm{K}$ ), though numbers were small. A contributory factor was the great reduction in category 1 cases, and it is now unusual for women not to receive anti-D immunoglobulin. When anti-D was first introduced in the 1970s it was common for it not to be given, particularly after termination of pregnancy. The reduction in category 2 cases may have been the result of increased use of antenatal anti-D, but we have no hard data on that point.

Interestingly, in the United States in 1987 the death rate from "haemolytic disease of the newborn due to isoimmunisation and other perinatal jaundice" was only $0 \cdot 7 / 100000$ live births whereas in England and Wales the death rate was $18 \cdot 4 / 100000$ live births in 1977 and $1.5 / 100000$ in $1989 .{ }^{2}$

A referee pointed out that in his region, although the death rates had decreased, new cases of anti-D sensitisation not resulting in death remained at a constant level, and we are investigating this in the Mersey region. Although it is important to continue to

the total number of cases notified in 1989 and confirmed as due to $\mathrm{Rh}$ haemolytic disease was only 10 . We therefore checked with the Office of Population Censuses and Surveys that there had been no change in the way cases had been registered in recent years and that all the certificates had been sent to us, and this in fact was the case. 